\title{
State of the Art in Adoption of Contact Tracing Apps and Recommendations Regarding Privacy Protection and Public Health: Systematic Review
}

Katarzyna Kolasa ${ }^{1}, \mathrm{PhD}$; Francesca Mazzi ${ }^{2,3}$, LLM; Ewa Leszczuk-Czubkowska ${ }^{4}$, MSc; Zsombor Zrubka ${ }^{5,6}$, MD, MBA, PhD; Márta Péntek ${ }^{5}$, Prof Dr, PhD

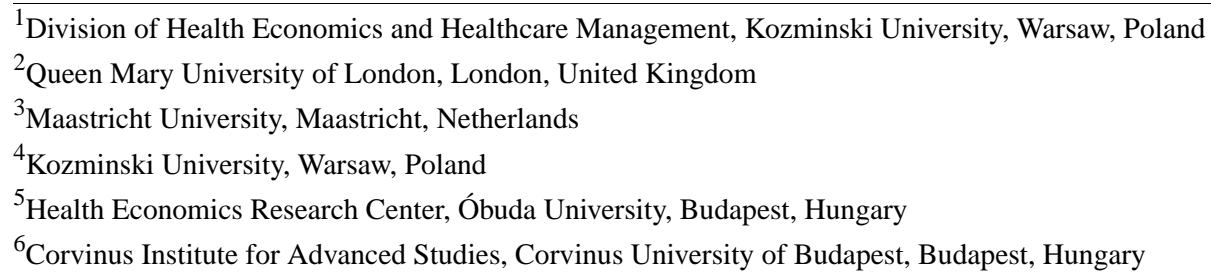

\section{Corresponding Author:}

Katarzyna Kolasa, $\mathrm{PhD}$

Division of Health Economics and Healthcare Management

Kozminski University

57/59 Jagiellonska St

Warsaw, 03-301

Poland

Phone: 48225192100

Email: kkolasa@kozminski.edu.pl

\section{Abstract}

Background: During the COVID-19 pandemic, contact tracing apps have received a lot of public attention. The ongoing debate highlights the challenges of the adoption of data-driven innovation. We reflect on how to ensure an appropriate level of protection of individual data and how to maximize public health benefits that can be derived from the collected data.

Objective: The aim of the study was to analyze available COVID-19 contact tracing apps and verify to what extent public health interests and data privacy standards can be fulfilled simultaneously in the process of the adoption of digital health technologies.

Methods: A systematic review of PubMed and MEDLINE databases, as well as grey literature, was performed to identify available contact tracing apps. Two checklists were developed to evaluate (1) the apps' compliance with data privacy standards and (2) their fulfillment of public health interests. Based on both checklists, a scorecard with a selected set of minimum requirements was created with the goal of estimating whether the balance between the objective of data privacy and public health interests can be achieved in order to ensure the broad adoption of digital technologies.

Results: Overall, 21 contact tracing apps were reviewed. In total, 11 criteria were defined to assess the usefulness of each digital technology for public health interests. The most frequently installed features related to contact alerting and governmental accountability. The least frequently installed feature was the availability of a system of medical or organizational support. Only 1 app out of $21(5 \%)$ provided a threshold for the population coverage needed for the digital solution to be effective. In total, 12 criteria were used to assess the compliance of contact tracing apps with data privacy regulations. Explicit user consent, voluntary use, and anonymization techniques were among the most frequently fulfilled criteria. The least often implemented criteria were provisions of information about personal data breaches and data gathered from children. The balance between standards of data protection and public health benefits was achieved best by the COVIDSafe app and worst by the Alipay Health Code app.

Conclusions: Contact tracing apps with high levels of compliance with standards of data privacy tend to fulfill public health interests to a limited extent. Simultaneously, digital technologies with a lower level of data privacy protection allow for the collection of more data. Overall, this review shows that a consistent number of apps appear to comply with standards of data privacy, while their usefulness from a public health perspective can still be maximized.

(JMIR Mhealth Uhealth 2021;9(6):e23250) doi: $\underline{10.2196 / 23250}$ 


\section{KEYWORDS}

COVID-19; contact tracing app; data accessibility; data privacy; mobile app; digital health; digital contact tracing

\section{Introduction}

The COVID-19 outbreak has shown how digital solutions can transform the health care system in an unprecedented manner. The rapid implementation of numerous innovative technologies to treat patients with COVID-19 has highlighted how much the human race can really benefit from data-driven transformation $[1,2]$.

However, not all digital solutions have been launched in a contiguous manner. A specific example in this case includes mobile technologies. In principle, there are three areas in which mobile phone apps could aid in the fight against the COVID-19 pandemic: (1) self-diagnosis and facilitating treatment, (2) monitoring and enforcing the quarantine of infected persons, and (3) signaling if one is in close contact with an infected person [3].

The app used in the third area is called a contact tracing app and uses a smartphone to create a memory of any close contact with others for a significant amount of time. A warning is sent in case an infection is registered for anyone from the memory list, notifying the phone's owner to get tested and possibly self-quarantine.

Despite ongoing challenges to limit the spread of the virus, the launch of such digital solutions still faces several hurdles. Meanwhile, digital contact tracing apps have enormous potential, given the fact that there are more than 3.5 billion mobile phone users worldwide. However, there is significant resistance to allowing such technologies to interfere in the lives of individuals. More than one hundred nongovernmental organizations and civil rights associations have urged governments not to use the pandemic as an excuse to enter a new era of digital surveillance [4].

In an effort to overcome potential privacy challenges in the adoption of contact tracing technologies, the European Data Protection Board (EDPD) has published guidance for the use of location data and contact tracing tools intended to mitigate the impact of the COVID-19 pandemic [3]. Moreover, Article 9 (2) of the General Data Protection Regulation (GDPR) allows for access to special categories of data if the processing of such data is necessary for reasons of public interest in the public health sector, such as protection from serious cross-border threats to health. However, such a possibility consists of neither the full compression of privacy rights nor the GDPR itself [5].

Hence, existing guidelines and principles available at the European level should be considered as safe tools to guide developers of digital solutions, even in critical times, so as to ensure the adequate respect of individuals' rights. On the other hand, considering that the public health benefit of contact tracing apps depends directly on their widespread use, it is desirable to have governments strive to build trust among citizens with a high level of transparency. The pandemic showed how individual health is strictly connected to others' health, and that one of the most effective measures in the absence of a vaccine is the behavior of the individual, for that one person as much as for the whole community.

Therefore, while it is desirable to develop an app that guarantees an adequate level of privacy, it is equally desirable that citizens feel the need to use such an app as an act of social responsibility toward themselves and the community in general.

In this context, the objective of our study was to address the following two questions: (1) How do available contact tracing apps allow for data collection for public health benefits and comply with standards of data privacy? and (2) Can the balance between public health interests and the protection of personal data be established to ensure the broad use of digital technologies?

The success or failure of the adoption of contact tracing apps will have impacts beyond the ongoing fight against the COVID-19 pandemic. It will set a precedent for future opportunities and challenges in the integration of other digital solutions into clinical practice while ensuring the data privacy of its users. Therefore, we hope that our conclusions and recommendations can contribute to the debate regarding the adoption of digital technologies in the support of solving health issues, even beyond challenges related to the COVID-19 pandemic.

\section{Methods}

\section{Systematic Review}

We first performed a literature search in PubMed, MEDLINE, IEEE (Institute of Electrical and Electronics Engineers), and ACM (Association for Computing Machinery) Digital Library databases, covering the period between January 1 and August 31, 2020. The following key phrases were applied: "contact tracing," "contact detector," "contact mapping and COVID-19," "COVID-2019," "severe acute respiratory syndrome coronavirus 2," "2019-nCoV," and "SARS-CoV-2." The search terms are included in Multimedia Appendix 1. Only research articles written in English presenting a specific contact tracing app were included. Other publications, such as news articles, editorials, commentaries, reviews, or letters, were excluded. No geographical restriction was imposed. The selection and review of included publications were conducted independently by two reviewers, and discrepancies were resolved by consensus. The PRISMA (Preferred Reporting Items for Systematic Reviews and Meta-Analyses) checklist was followed [6].

\section{Supplementary Search}

A supplementary search on the GitHub repository, as well as on governmental and app webpages, was then performed separately to collect additional information related to contact tracing apps that were identified in the systematic literature review. The following terms were screened: (1) overview, (2) frequently asked questions (FAQ), (3) data privacy, and (4) terms of use. 


\section{Assessment of the Fulfillment of Public Health Interests and Compliance With Data Privacy Guidelines}

In order to address the first research question, two checklists were then developed to ensure a standardized approach toward the review of each technology. Both were sourced based on external reports in the fields of interest. The first checklist was constructed to review the key functions of mobile apps that define their fulfillment of public health interests. It was based on the Ada Lovelace Institute's report [7]. The second checklist was constructed to verify the compliance of contact tracing apps with selected data privacy standards. The following European guidelines were adopted in that respect: (1) the Privacy Code of Conduct for mobile health apps from the European Commission [8] and (2) the guidelines on the use of location data and contact tracing tools in the context of the COVID-19 outbreak from the EDPD [9]. The definition of each data privacy criterion that was used is available in Multimedia Appendix 2.

\section{Balance Between Data Privacy and Public Health Interests}

Finally, in order to address the second research question, a set of minimum requirements that simultaneously fulfill objectives of data privacy and public health was constructed. All reviewed contact tracing apps were ranked. The score of 1 or -1 was applied for each condition being met or not met, respectively. In the absence of information, a score of 0 was assigned. All requirements were considered as equally important. The ranking of all the reviewed technologies was constructed based on the number of scores granted.

\section{Results}

\section{Systematic Review and Supplementary Research Eligibility}

Overall, 611 unique records were identified across three databases, of which 531 articles did not meet the inclusion criteria (Figure 1). The abstract review of 80 full-text publications led to the exclusion of a further 33 articles (Multimedia Appendix 3). As the result of the full-text review of the remaining 47 publications, 38 different contact tracing apps were identified. Out of these 38 mobile apps, 17 were further excluded due to the unavailability of downloadable systems $(n=11)$, a lack of sufficient information needed to perform the study $(n=4)$, and not meeting criteria for contact tracing technology $(n=2)$ (Figure 1). Further reasons for the exclusion of apps are provided in Multimedia Appendix 4 [10-42]. In the final set, 21 digital technologies were included. Among them were $18(86 \%)$ and $3(14 \%)$ apps that were used nationally and internationally, respectively. Additional information was collected from 34 supplementary references: government websites $(n=7)$, app websites $(n=13)$, academic articles $(n=3)$, and GitHub ( $n=11)$ (Multimedia Appendix 5). 
Figure 1. Flowchart of the article selection process for the literature search. ACM: Association for Computing Machinery; IEEE: Institute of Electrical and Electronics Engineers.

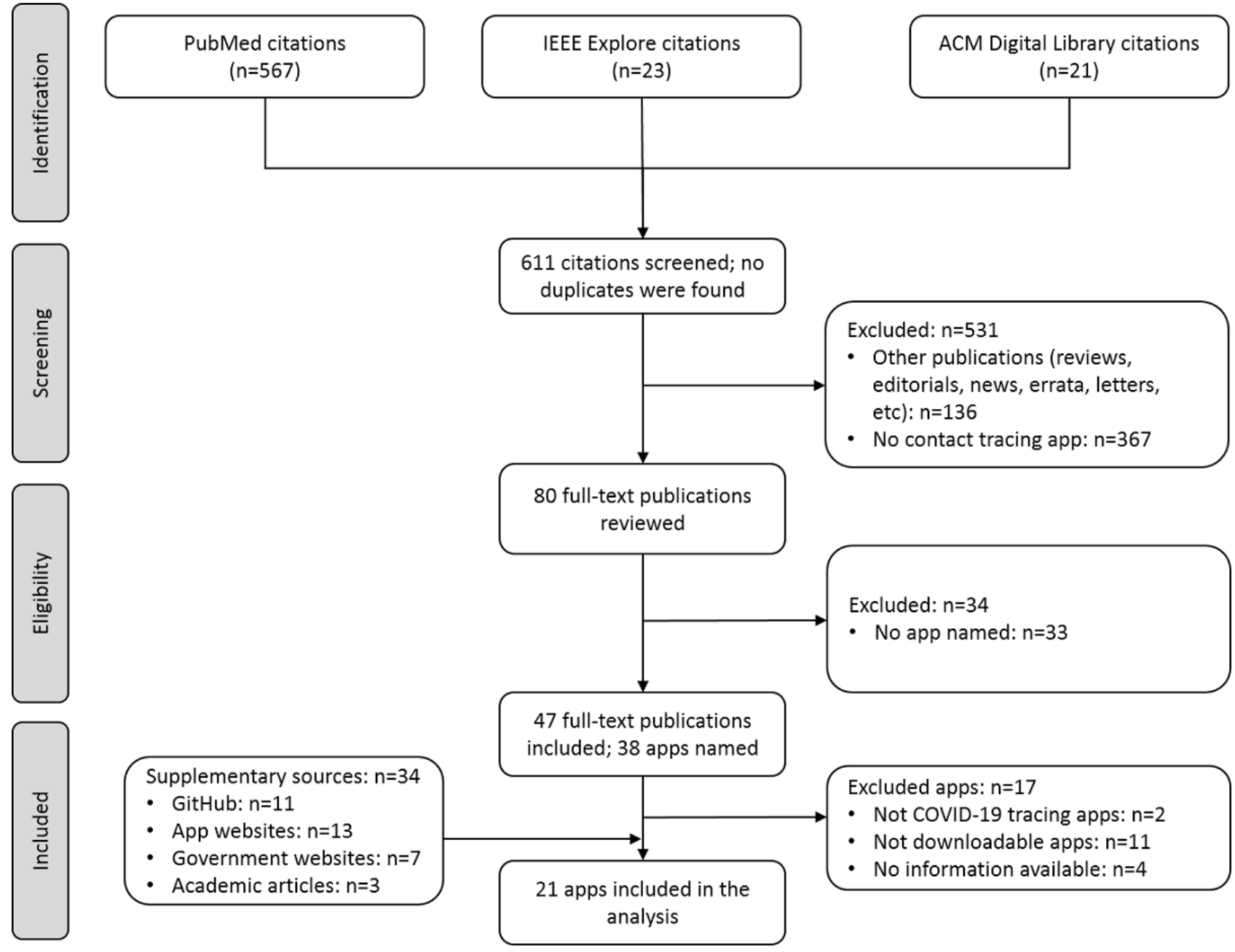

\section{Assessment of the Apps' Fulfillment of Public Health Interests}

In total, 11 criteria were defined to assess how digital technologies were able to fulfill public health interests. The three most frequently adopted types of functions in the group of reviewed contact tracing apps were (1) information about geographical coverage, (2) contact alerting, and (3) governmental responsibility. The two least frequently adopted functions were (1) medical and organizational support and (2) efficiency threshold (Multimedia Appendix 6 [10-27,43-56]). Out of the 21 apps, 19 (90\%) received support from governments, but only $1(5 \%)$ provided the additional threshold required to establish an app's efficiency. A confirmation of diagnosis with COVID-19 was required in 20 out of 21 (95\%) cases, and $5(24 \%)$ apps offered the possibility to register symptoms of COVID-19, such as fever, cough, or dyspnea. In 11 cases out of 21 (52\%), the recommendation to self-isolate was issued. Other types of proximity data, such as recent travel, potentially related disorders, possible point of contact, and risk factors such as chronic disorders, were collected in half of apps as well (11/21, 52\%) (Multimedia Appendix 6). Alipay Health Code was the only app that collected data about medical treatment; however, no details were found in that respect. Public health authorities and employers could access data stored in 10
(48\%) and $1(5 \%)$ contact tracing apps, respectively. Finally, there were two forms of support offered through contact tracing apps: a symptom checker and health care coordination (Multimedia Appendix 6).

\section{Assessment of the Apps' Compliance With Data Privacy Guidelines}

In total, 12 criteria were defined to verify to what extent digital technologies complied with data privacy guidelines. The three most frequently met conditions were (1) user consent, (2) voluntary basis, and (3) adoption of anonymization techniques (Multimedia Appendix 7 [10-27,43-56]). The provisions of information about (1) personal data breaches, (2) data gathered from children, and (3) confirmation of no data sharing to third parties were the least often implemented (Multimedia Appendix 7). As far as adequate security measures were concerned, 16 out of 21 (76\%) contact tracing apps used a decentralized approach and $2(10 \%)$ used a centralized approach. The remaining $3(14 \%)$ apps did not provide such information. Moreover, 14 out of 21 (67\%) apps published their code in the GitHub open source repository (Multimedia Appendix 7). Out of the 21 cases, 10 (48\%) used anonymization techniques, with encryption methods being employed in 14 (67\%) (Multimedia Appendix 7). Among other techniques, data aggregation, hashing algorithms, and asymmetrical unique keys were identified. 
Furthermore, 15 of the 21 (74\%) apps used pseudo-random (ie, frequently changing and ephemeral) identifiers as a method to ensure cybersecurity. This method suggests that the temporary ID of each device is created and modified periodically. Bluetooth appeared to be the most common method, which was adopted in 18 of the $21(86 \%)$ apps, while 5 (24\%) used GPS only, or in addition to Bluetooth. Regarding data retention, the average period of retention of proximity data was 3 weeks (Multimedia Appendix 7). Finally, 13 out of 21 (62\%) apps used a mechanism to verify COVID-19-positive results, specifically verification through a code sent to a mobile phone or confirmed by health care professionals (Multimedia Appendix 7).

\section{Balance Between Data Protection and Public Health Interests}

The set of 10 and 6 minimum requirements related to data privacy and public health interests, respectively, were defined to assess the balance between these two domains (Multimedia Appendix 8). None of the analyzed apps managed to comply with all 16 conditions. COVIDSafe and SwissCovid met all 10 data privacy requirements and 5 out of 6 criteria for fulfillment of public health interests (15 points). The worst performance was achieved by Alipay Health Code ( -3 points). Among the reviewed technologies, the standards of governmental accountability, anonymization, and encryption were the most frequently fulfilled. The establishment of an efficiency threshold and the adoption of rules against data breaches were the criteria with the lowest compliance.

\section{Discussion}

\section{Principal Findings}

The success of the digital revolution in the health care sector depends on access to a consistent volume of quality data that are useful to medical advancement, while ensuring an appropriate level of protection of personal data privacy. In our research, we attempted to systematically analyze the state of the art in the adoption of contact tracing apps in the fight against the COVID-19 pandemic, with the objective to verify to what extent the requirements concerning data protection and public health interests can be achieved simultaneously.

In order to develop the comprehensive list of criteria for our analysis, we searched the public domain for available guidelines in the fields of interest. We adopted a human-centered approach in that respect, which should be interpreted from two perspectives.

Firstly, when addressing the type of data being collected, we strived to choose the most comprehensive set of criteria that would ensure the maximization of public health benefit from a societal perspective. Therefore, we deliberately selected the Ada Lovelace Institute's report, which is based on the core values and the underlying mission of the institute (ie, to ensure that data and artificial intelligence work for people and society) [7].

Secondly, when addressing data protection, we focused on guidelines that were developed based on the most

comprehensive set of data protection rules, such as the GDPR. From the European perspective, data protection is, in fact, considered a fundamental human right. Hence, we selected (1) the Privacy Code of Conduct on mobile health apps from the European Commission [8] and (2) the guidelines on the use of location data and contact tracing tools in the context of the COVID-19 outbreak from the EDPD. The GDPR is a regulation (ie, directly effective for member states without the need of further national laws) that concerns all types of processing of personal data and it applies to entities that process the personal data of European citizens. Hence, compliance with the GDPR is to be considered implicit for all European apps. The two selected legal instruments have a different level of authority, being a set of guidelines and a code of conduct, which means that developers can voluntarily commit to follow the rules. Hence, we decided to evaluate to what extent such rules- that we considered relevant in relation to contact tracing apps- have been followed by developers. Let us note that contact tracing apps can be considered mobile health technologies for two reasons: (1) information about COVID-19 positivity equates to health data and (2) there often are other consequences when the app sends a notification about contact with a positive case (eg, the receiver has a recommendation to self-isolate, whereas others need to contact health care providers). Hence, these consequences may be equivalent to the notion of providing health advice.

Not only did we develop the set of criteria for our analysis based on the chosen guidelines, but we also constructed a scorecard that simultaneously evaluated compliance with data protection and the level of fulfillment of public health benefits. It should be noted that although we did assign the same weight to all minimum requirements on the scorecard, we do value data protection as an essential condition due to the recognition of privacy as a human right and the urge to prevent a surveillance society. Hence, from our perspective, meeting the data protection criteria should be recommended as the mandatory base upon which to build digital health solutions and, consequently, public health benefits.

In sum, we reviewed 37 records about 21 contact tracing apps. In total, 12 and 11 criteria were used for the assessment of compliance with data privacy and fulfillment with public health interests, respectively. There are three key important findings worth highlighting.

Firstly, the majority of reviewed contact tracing apps were, to a greater extent, compliant with data privacy standards. As many as 18 out of $21(86 \%)$ apps were designed to be used on a voluntary basis. Such an approach should be considered as optimal because it prevents any discrimination against individuals who are unable or unwilling to download the app. Moreover, the mandatory use of digital technology could lead to financial and technical burdens. Hence, jurisdictions with mandatory use of such apps are actually not compliant with the European standards. As demonstrated in Multimedia Appendix 7, BeAware Bahrain, Alipay Health Code, and Aarogya Setu were part of this category. A consistent number of apps used the decentralized approach $(16 / 21,76 \%)$, which is preferable to the centralized approach from a cybersecurity perspective. Additionally, Bluetooth technology with changing ephemeral 
identifiers was employed in 15 out of $21(71 \%)$ cases, which is preferable to GPS for privacy reasons, as Bluetooth is less intrusive. Still, there is room for improvement with respect to compliance with data privacy; in addition, the rules against data breaches were provided in only 3 out of 21 (14\%) cases.

Secondly, as far as public health interests are concerned, there is still room for improvement among contact tracing apps. Only 8 out of $21(38 \%)$ apps provided the definition of close contact, and governmental accountability was limited to 19 out of 21 (90\%) cases. Additionally, 10 out of 21 (48\%) apps reviewed solutions that were allowed for data accessibility for health care professionals. In that group, only 8 out of $10(80 \%)$ apps provided details regarding techniques used for data aggregation, encryption, and/or anonymization. Meanwhile, there were just 13 out of $21(62 \%)$ apps that used the mechanism of diagnosis verification, and the threshold for the population coverage needed for the digital solution to be effective was provided only once.

Thirdly, we observed the tendency that, with a high level of compliance with data privacy regulations, public health interests could be achieved to a limited extent, whereas a lower level of compliance with data privacy occurred across cases with greater potential for data collection. The COVIDSafe and SwissCovid apps met 15 out of 16 requirements. Both ensured that the minimum amount of data necessary for contact tracing was collected (ie, proximity data through Bluetooth). Contrary to that, Alipay Health Code ranked last in the scorecard as it processed a vast amount of data. Such a difference seems to be linked with different cultural, geographic, and political backgrounds. In principle, collecting more data could be useful from a public health perspective, for example, in order to closely monitor the contagion or to have a clearer and bigger picture of the spread of the disease from an epidemiological standpoint. Nonetheless, in relation to Alipay Health Code, no information was found about the actual use of the collected data for public health purposes. The lack of information available to users concerning the use of their data for further public health purposes would not, per se, infringe on the European principles as expressed in the GDPR. Indeed, Article 5.1 (b) of the GDPR considers further processing of collected data for public interest as compatible with the initial purpose of processing. Nonetheless, from a policy perspective, such ambiguity about the use of personal data might not be desirable in the European environment. In fact, not only might it disincentivize the use of apps due to the lack of transparency, but it could also have detrimental effects on society by undermining trust between citizens and governments.

Our findings need to be regarded with caution due to certain limitations of our study that must be acknowledged. Firstly, given the dynamic pandemic situation, we are aware that new developments in the field occur on a daily basis; as such, a number of new contact tracing apps were published after our systematic literature review was completed, or they were excluded due to limited information. On that note, it is worth mentioning that one of the most downloaded apps in the United States, namely HealthLynked COVID-19 Tracker [57,58], was not included in our study due to a lack of accessible information. Indeed, no sufficient information in relation to privacy and public health conditions was available in order to include the app in our tables. In fact, the website of the developer does not provide technical details nor a dedicated privacy policy for the tracking app; only the general privacy policy for other pre-existing HealthLynked apps was found. In our view, such disconnection between information provided to users and users' downloads of the app raises serious privacy concerns and does not constitute a good practice for future developers.

Secondly, let us highlight that our checklists were based on specific references, while there have been other relevant guidelines already developed in relation to COVID-19 contact tracing apps. An example in this case is the article Ethical guidelines for COVID-19 tracing apps, which was already published in Nature by a group of researchers from the University of Oxford after our study had been completed [10]. Such guidelines include not only principles of privacy but also relevant ethical issues, such as equality in the access to digital technology, which we do not discuss in our publication.

Thirdly, we deliberately omitted the assessment of effectiveness of reviewed contact tracing apps, as this was already published by other authors [59].

Finally, although we used a global approach to search for apps, our analysis was conducted from a European perspective. Non-European jurisdictions have diverse cultural and political backgrounds and, as such, may follow different sets of values [60]. Even before the COVID-19 outbreak, it had been routine to undergo temperature checks before visiting public places, maintain social distancing, and wear masks in some non-European countries [60]. Their technological apparatus is entirely different from the European one, as is the level of citizens' trust for the government. Accordingly, solutions adopted in such countries are not necessarily easily applicable in European settings and vice versa [60].

\section{Conclusions}

Despite the above limitations, we hope that our results and conclusions will inspire approaches on how to develop digital health solutions and ensure their broad adoption. Our literature review indicated that a consistent number of apps appear to be substantially compliant with the standards of data privacy, while the usefulness of contact tracing technologies from the public health perspective can still be maximized. Available surveys indicate that attitudes toward the use of contact tracing apps vary across different jurisdictions. According to a University of Oxford survey, the acceptance rate for contact tracing apps ranged from $67.5 \%$ to $85.5 \%$ in France, Germany, and Italy [61]. Conversely, a Pew Research Center study found that $60 \%$ of Americans believe that location tracking will not help limit the spread of COVID-19, and only $45 \%$ believe that such an app is allowed to track citizens who have had contact with an infected person [62]. Still, available estimates indicate that more than half of the population should use such an app in order to provide public health benefits [63]. Therefore, the question is how to ensure the broad adoption of contact tracing apps when their adoption happens on a voluntary basis, as was the case in 18 out of the $21(86 \%)$ reviewed technologies. At the same time, only 1 of the $21(5 \%)$ reviewed contact tracing apps provided information regarding the threshold for its efficiency in 
combatting the COVID-19 pandemic. Consequently, the ultimate objective can be defined as the need to establish an evidence-based approach to the definition of the broad use of contact tracing apps and an educational campaign about their benefits. Indeed, mandatory use of digital health solutions would undermine the right to personal freedom that characterizes democratic societies. Another recent global survey on 7804 respondents from seven countries revealed that as many as $41 \%$ of the study population indicated data security as the number one barrier to adopting digital solutions. The adoption of the decentralized approach, which was the case for 16 out of 21 (76\%) apps, may provide a better chance to obtain the required trust among end users [64].

Overall, a prima facie analysis suggests that the more intrusive the government is into an individual's privacy, the more that public health can benefit from the data. Moreover, it seems that a high level of privacy protection corresponds to an obstacle in terms of the use of data for public health. Nonetheless, we argue that the two interests can be perceived as not contradictory. Indeed, digital health solutions that protect individuals' privacy can be directed toward optimization of public health benefits. To achieve such a goal, the adoption of transparency policies that increase trust between public and private stakeholders should be encouraged. In fact, solid public confidence in digital solutions developed by governments that prioritize the protection of the rights of individuals can foster further data sharing for public health purposes, among other things.

Indeed, we believe that the key success factors in this matter are transparency and information campaigns targeting individuals, which can be achieved by working toward an awareness of citizens' responsibility and by providing relevant information on data protection and cybersecurity. Fostering citizen involvement in public matters such as public health can help to make every individual feel like a member of the state. Such awareness would stimulate individuals to share their data in a controlled and safe environment for the benefit of society.

\section{Acknowledgments}

During the conduct of this research, ZZ has received funding from the European Research Council under the European Union's Horizon 2020 research and innovation program (grant 679681). This research was implemented with the support provided from the National Research, Development and Innovation Fund of Hungary, financed under the Tématerületi Kiválósági Program funding scheme (project No. TKP2020-NKA-02). MP has received funding from project No. 2019-1.3.1-KK-2019-00007, implemented with the support provided from the National Research, Development and Innovation Fund of Hungary, financed under the 2019-1.3.1-KK funding scheme. FM received funding from the European Intellectual Property Institutes Network-Innovation Society (EIPIN IS) project funded by the European Union's Horizon 2020 research and innovation program under the Marie Skłodowska-Curie grant (agreement No. 721733).

\section{Conflicts of Interest}

None declared.

\section{Multimedia Appendix 1}

Search terms for the systematic review. [DOCX File, 13 KB-Multimedia Appendix 1]

\section{Multimedia Appendix 2}

Definitions of data privacy standard criteria.

[DOCX File , 25 KB-Multimedia Appendix 2]

\section{Multimedia Appendix 3}

Reasons for exclusion of full-text articles. [DOCX File, 16 KB-Multimedia Appendix 3]

\section{Multimedia Appendix 4}

Reasons for exclusion of apps. [DOCX File , 55 KB-Multimedia Appendix 4]

\section{Multimedia Appendix 5}

Supplementary sources of information. 


\section{Multimedia Appendix 6}

Assessment of public health interests.

[DOCX File, 78 KB-Multimedia Appendix 6]

\section{Multimedia Appendix 7}

Assessment of data privacy.

[DOCX File, 94 KB-Multimedia Appendix 7]

\section{Multimedia Appendix 8}

Ranking of apps.

[XLSX File (Microsoft Excel File), 22 KB-Multimedia Appendix 8]

\section{References}

1. Mońko M, Collins S. AI app, part-funded by EU, collects the sounds of COVID-19. European Research Council. 2020 Apr 06. URL: https://erc.europa.eu/news/ ai-app-part-funded-eu-collects-sounds-covid-19?fbclid=IwAR2wQUYAI 8nsBqI2 YJgH2N1XaRNfQUq5VeECu891-6Mqd8iexJJ9Eq2XI [accessed 2020-05-08]

2. Siwicki B. Americans' perceptions of telehealth in the COVID-19 era. Healthcare IT News. 2020 Apr 03. URL: https:/ /www.healthcareitnews.com/news/survey-americans-perceptions-telehealth-covid-19-era [accessed 2020-05-08]

3. Commission recommendation (EU) 2020/518 of 8 April 2020 on a common Union toolbox for the use of technology and data to combat and exit from the COVID-19 crisis, in particular concerning mobile applications and the use of anonymized mobility data. European Union. 2020 Apr 08. URL: https://op.europa.eu/pl/publication-detail/-/publication/ 1e8b1520-7e0c-11ea-aea8-01aa75ed71a1/language-en [accessed 2020-05-05]

4. Digital surveillance to fight COVID-19 can only be justified if it respects human rights. Amnesty International. 2020 Apr 02. URL: https://www.amnesty.org/en/latest/news/2020/04/covid19-digital-surveillance-ngo/ [accessed 2020-05-10]

5. Regulation (EU) 2016/679 of the European Parliament and of the Council of 27 April 2016 on the protection of natural persons with regard to the processing of personal data and on the free movement of such data, and repealing Directive 95/46/EC (General Data Protection Regulation). Eur-Lex. 2016 Apr 27. URL: https://eur-lex.europa.eu/eli/reg/2016/679/ oj [accessed 2020-05-05]

6. Moher D, Liberati A, Tetzlaff J, Altman DG, PRISMA Group. Preferred reporting items for systematic reviews and meta-analyses: The PRISMA statement. PLoS Med 2009 Jul 21;6(7):e1000097 [FREE Full text] [doi:

10.1371/journal.pmed.1000097] [Medline: 19621072]

7. Exit through the App Store? Rapid evidence review. Ada Lovelace Institute. London, UK: Ada Lovelace Institute; 2020 Apr 20. URL: https://www.adalovelaceinstitute.org/wp-content/uploads/2020/04/ Ada-Lovelace-Institute-Rapid-Evidence-Review-Exit-through-the-App-Store-April-2020-2.pdf [accessed 2020-05-05]

8. Privacy code of conduct on mobile health apps. European Commission. URL: https://ec.europa.eu/digital-single-market/ en/privacy-code-conduct-mobile-health-apps [accessed 2020-05-04]

9. Guidelines 04/2020 on the Use of Location Data and Contact Tracing Tools in the Context of the COVID-19 Outbreak. Brussels, Belgium: European Data Protection Board; 2020 Apr 21. URL: https://edpb.europa.eu/sites/default/files/files/ file1/edpb guidelines 20200420 contact tracing covid with annex en.pdf [accessed 2020-05-15]

10. Morley J, Cowls J, Taddeo M, Floridi L. Ethical guidelines for COVID-19 tracing apps. Nature 2020 Jun;582(7810):29-31. [doi: 10.1038/d41586-020-01578-0] [Medline: $\underline{\text { 32467596] }}$

11. Mbunge E. Integrating emerging technologies into COVID-19 contact tracing: Opportunities, challenges and pitfalls. Diabetes Metab Syndr 2020;14(6):1631-1636 [FREE Full text] [doi: 10.1016/j.dsx.2020.08.029] [Medline: $\underline{32892060]}$

12. Maghdid HS, Ghafoor KZ. A smartphone enabled approach to manage COVID-19 lockdown and economic crisis. SN Comput Sci 2020;1(5):271 [FREE Full text] [doi: 10.1007/s42979-020-00290-0] [Medline: 33063052]

13. Ahmed N, Michelin RA, Xue W, Ruj S, Malaney R, Kanhere SS, et al. A survey of COVID-19 contact tracing apps. IEEE Access 2020;8:134577-134601. [doi: 10.1109/access.2020.3010226]

14. Garg L, Chukwu E, Nasser N, Chakraborty C, Garg G. Anonymity preserving IoT-based COVID-19 and other infectious disease contact tracing model. IEEE Access 2020;8:159402-159414. [doi: 10.1109/access.2020.3020513]

15. Bradford L, Aboy M, Liddell K. COVID-19 contact tracing apps: A stress test for privacy, the GDPR, and data protection regimes. J Law Biosci 2020;7(1):1saa034 [FREE Full text] [doi: 10.1093/jlb/lsaa034] [Medline: $\underline{32728470}$ ]

16. Kricka LJ, Polevikov S, Park JY, Fortina P, Bernardini S, Satchkov D, et al. Artificial intelligence-powered search tools and resources in the fight against COVID-19. EJIFCC 2020 Jun;31(2):106-116 [FREE Full text] [Medline: 32549878]

17. Lin L, Hou Z. Combat COVID-19 with artificial intelligence and big data. J Travel Med 2020 Aug 20;27(5):taaa080 [FREE Full text] [doi: 10.1093/jtm/taaa080] [Medline: $\underline{\text { 32437541] }}$ 
18. Schneble CO, Elger BS, Martin Shaw D. Data protection during the coronavirus crisis. EMBO Rep 2020 Sep 03;21(9):e51362 [FREE Full text] [doi: 10.15252/embr.202051362] [Medline: $\underline{\text { 32783305] }}$

19. Leins K, Culnane C, Rubinstein BI. Tracking, tracing, trust: Contemplating mitigating the impact of COVID-19 with technological interventions. Med J Aust 2020 Jul;213(1):6-8.e1 [FREE Full text] [doi: 10.5694/mja2.50669] [Medline: 32548879]

20. Wise J. Covid-19: UK drops its own contact tracing app to switch to Apple and Google model. BMJ 2020 Jun 19;369:m2472. [doi: 10.1136/bmj.m2472] [Medline: 32561511]

21. Park YJ, Cho SY, Lee J, Lee I, Park W, Jeong S, et al. Development and utilization of a rapid and accurate epidemic investigation support system for COVID-19. Osong Public Health Res Perspect 2020 Jun;11(3):118-127 [FREE Full text] [doi: 10.24171/j.phrp.2020.11.3.06] [Medline: 32528817]

22. Nuzzo A, Tan CO, Raskar R, DeSimone DC, Kapa S, Gupta R. Universal shelter-in-place versus advanced automated contact tracing and targeted isolation: A case for 21st-century technologies for SARS-CoV-2 and future pandemics. Mayo Clin Proc 2020 Sep;95(9):1898-1905 [FREE Full text] [doi: 10.1016/j.mayocp.2020.06.027] [Medline: 32861334]

23. Almeida BDA, Doneda D, Ichihara MY, Barral-Netto M, Matta GC, Rabello ET, et al. Personal data usage and privacy considerations in the COVID-19 global pandemic. Cien Saude Colet 2020 Jun;25(suppl 1):2487-2492 [FREE Full text] [doi: 10.1590/1413-81232020256.1.11792020] [Medline: 32520293 ]

24. Yasaka TM, Lehrich BM, Sahyouni R. Peer-to-peer contact tracing: Development of a privacy-preserving smartphone app. JMIR Mhealth Uhealth 2020 Apr 07;8(4):e18936 [FREE Full text] [doi: 10.2196/18936] [Medline: $\underline{32240973}$ ]

25. Hernandez-Orallo E, Manzoni P, Calafate CT, Cano J. Evaluating how smartphone contact tracing technology can reduce the spread of infectious diseases: The case of COVID-19. IEEE Access 2020;8:99083-99097. [doi: 10.1109/access.2020.2998042]

26. Rowe F. Contact tracing apps and values dilemmas: A privacy paradox in a neo-liberal world. Int J Inf Manage 2020 Dec;55:102178 [FREE Full text] [doi: 10.1016/j.ijinfomgt.2020.102178] [Medline: 32836636]

27. Gasser U, Ienca M, Scheibner J, Sleigh J, Vayena E. Digital tools against COVID-19: Taxonomy, ethical challenges, and navigation aid. Lancet 2020 Aug;2(8):e425-e434.

28. Wilmink G, Summer I, Marsyla D, Sukhu S, Grote J, Zobel G, et al. Real-time digital contact tracing: Development of a system to control COVID-19 outbreaks in nursing homes and long-term care facilities. JMIR Public Health Surveill 2020 Aug 25;6(3):e20828 [FREE Full text] [doi: 10.2196/20828] [Medline: 32745013]

29. Vokinger KN, Nittas V, Witt CM, Fabrikant SI, von Wyl V. Digital health and the COVID-19 epidemic: An assessment framework for apps from an epidemiological and legal perspective. Swiss Med Wkly 2020 May 04;150:w20282 [FREE Full text] [doi: 10.4414/smw.2020.20282] [Medline: 32418194]

30. Fahey RA, Hino A. COVID-19, digital privacy, and the social limits on data-focused public health responses. Int J Inf Manage 2020 Dec;55:102181 [FREE Full text] [doi: 10.1016/j.ijinfomgt.2020.102181] [Medline: $\underline{32836638}$ ]

31. Cohen IG, Gostin LO, Weitzner DJ. Digital smartphone tracking for COVID-19: Public health and civil liberties in tension. JAMA 2020 Jun 16;323(23):2371-2372. [doi: 10.1001/jama.2020.8570] [Medline: 32459289]

32. Sharon T. Blind-sided by privacy? Digital contact tracing, the Apple/Google API and big tech's newfound role as global health policy makers. Ethics Inf Technol 2020 Jul 18:1-13 [FREE Full text] [doi: 10.1007/s10676-020-09547-x] [Medline: $\underline{32837287]}$

33. Martinez-Martin N, Wieten S, Magnus D, Cho MK. Digital contact tracing, privacy, and public health. Hastings Cent Rep 2020 May;50(3):43-46 [FREE Full text] [doi: 10.1002/hast.1131] [Medline: 32596893]

34. White L, van Basshuysen P. How to overcome lockdown: Selective isolation versus contact tracing. J Med Ethics 2020 Nov;46(11):724-725 [FREE Full text] [doi: 10.1136/medethics-2020-106680] [Medline: $\underline{32817409]}$

35. Baraniuk C. Covid-19 contact tracing: A briefing. BMJ 2020 May 13;369:m1859. [doi: 10.1136/bmj.m1859] [Medline: 32404304]

36. Hegde A, Masthi R. Digital contact tracing in the COVID-19 pandemic: A tool far from reality. Digit Health 2020;6:1-3 [FREE Full text] [doi: 10.1177/2055207620946193] [Medline: 32939289]

37. Labs J, Terry S. Privacy in the coronavirus era. Genet Test Mol Biomarkers 2020 Sep;24(9):535-536. [doi: 10.1089/gtmb.2020.29055.sjt] [Medline: $\underline{32677850]}$

38. Nguyen CT, Saputra YM, Van Huynh N, Nguyen N, Khoa TV, Tuan BM, et al. A comprehensive survey of enabling and emerging technologies for social distancing-Part II: Emerging technologies and open issues. IEEE Access 2020;8:154209-154236. [doi: 10.1109/access.2020.3018124]

39. Nguyen CT, Saputra YM, Huynh NV, Nguyen N, Khoa TV, Tuan BM, et al. A comprehensive survey of enabling and emerging technologies for social distancing-Part I: Fundamentals and enabling technologies. IEEE Access 2020;8:153479-153507. [doi: 10.1109/access.2020.3018140]

40. Kleinman RA, Merkel C. Digital contact tracing for COVID-19. CMAJ 2020 Jun 15;192(24):E653-E656 [FREE Full text] [doi: 10.1503/cmaj.200922] [Medline: 32461324]

41. Kaspar K. Motivations for social distancing and app use as complementary measures to combat the COVID-19 pandemic: Quantitative survey study. J Med Internet Res 2020 Aug 27;22(8):e21613 [FREE Full text] [doi: 10.2196/21613] [Medline: $\underline{32759100]}$ 
42. Ho HJ, Zhang ZX, Huang Z, Aung AH, Lim W, Chow A. Use of a real-time locating system for contact tracing of health care workers during the COVID-19 pandemic at an infectious disease center in Singapore: Validation study. J Med Internet Res 2020 May 26;22(5):e19437 [FREE Full text] [doi: 10.2196/19437] [Medline: 32412416]

43. Gupta R, Bedi M, Goyal P, Wadhera S, Verma V. Analysis of COVID-19 tracking tool in India. Digit Gov 2020 Dec 03;1(4):1-8. [doi: $10.1145 / 3416088$ ]

44. Baumgart DC. Digital advantage in the COVID-19 response: Perspective from Canada's largest integrated digitalized healthcare system. NPJ Digit Med 2020;3:114 [FREE Full text] [doi: 10.1038/s41746-020-00326-y] [Medline: 32923691]

45. Ye Q, Zhou J, Wu H. Using information technology to manage the COVID-19 pandemic: Development of a technical framework based on practical experience in China. JMIR Med Inform 2020 Jun 08;8(6):e19515 [FREE Full text] [doi: 10.2196/19515] [Medline: 32479411]

46. Lucivero F, Hallowell N, Johnson S, Prainsack B, Samuel G, Sharon T. COVID-19 and contact tracing apps: Ethical challenges for a social experiment on a global scale. J Bioeth Inq 2020 Dec;17(4):835-839 [FREE Full text] [doi: 10.1007/s11673-020-10016-9] [Medline: 32840842]

47. Owusu PN. Digital technology applications for contact tracing: The new promise for COVID-19 and beyond? Glob Health Res Policy 2020;5:36 [FREE Full text] [doi: 10.1186/s41256-020-00164-1] [Medline: 32766453]

48. Ferretti L, Wymant C, Kendall M, Zhao L, Nurtay A, Abeler-Dörner L, et al. Quantifying SARS-CoV-2 transmission suggests epidemic control with digital contact tracing. Science 2020 May 08;368(6491):eabb6936 [FREE Full text] [doi: 10.1126/science.abb6936] [Medline: 32234805]

49. Ekong I, Chukwu E, Chukwu M. COVID-19 mobile positioning data contact tracing and patient privacy regulations: Exploratory search of global response strategies and the use of digital tools in Nigeria. JMIR Mhealth Uhealth 2020 Apr 27;8(4):e19139 [FREE Full text] [doi: 10.2196/19139] [Medline: 32310817]

50. Braun P, Haffner S, Woodcock BG. COVID-19 pandemic predictions using the modified Bateman SIZ model and observational data for Heidelberg, Germany: Effect of vaccination with a SARS-CoV-2 vaccine, coronavirus testing and application of the Corona-Warn-App. Int J Clin Pharmacol Ther 2020 Aug;58(8):417-425. [doi: 10.5414/CP203846] [Medline: 32646540]

51. Couch DL, Robinson P, Komesaroff PA. COVID-19-extending surveillance and the panopticon. J Bioeth Inq 2020 Dec;17(4):809-814 [FREE Full text] [doi: 10.1007/s11673-020-10036-5] [Medline: 32840859]

52. Currie DJ, Peng CQ, Lyle DM, Jameson BA, Frommer MS. Stemming the flow: How much can the Australian smartphone app help to control COVID-19? Public Health Res Pract 2020 Jun 30;30(2):1-11 [FREE Full text] [doi: 10.17061/phrp3022009] [Medline: 32601652]

53. Iacobucci G. Covid-19: Is local contact tracing the answer? BMJ 2020 Aug 17;370:m3248. [doi: 10.1136/bmj.m3248] [Medline: $\underline{\text { 32816820] }}$

54. Ryan BJ, Coppola D, Williams J, Swienton R. COVID-19 contact tracing solutions for mass gatherings. Disaster Med Public Health Prep 2020 Jul 14:1-7 [FREE Full text] [doi: 10.1017/dmp.2020.241] [Medline: 32660677]

55. Wallentin G, Kaziyeva D, Reibersdorfer-Adelsberger E. COVID-19 intervention scenarios for a long-term disease management. Int J Health Policy Manag 2020 Dec 01;9(12):508-516 [FREE Full text] [doi: 10.34172/ijhpm.2020.130] [Medline: 32729281]

56. Alwashmi MF. The use of digital health in the detection and management of COVID-19. Int J Environ Res Public Health 2020 Apr 23;17(8):2906 [FREE Full text] [doi: 10.3390/ijerph17082906] [Medline: 32340107]

57. Ming LC, Untong N, Aliudin NA, Osili N, Kifli N, Tan CS, et al. Mobile health apps on COVID-19 launched in the early days of the pandemic: Content analysis and review. JMIR Mhealth Uhealth 2020 Sep 16;8(9):e19796 [FREE Full text] [doi: 10.2196/19796] [Medline: $\underline{\text { 32609622] }}$

58. Brewster T. Google bans coronavirus infection trackers... but not before they get 400,000 downloads. Forbes. 2020 Mar 24. URL: https://www.forbes.com/sites/thomasbrewster/2020/03/24/ google-bans-coronavirus-apps-but-after-400000-downloads/?sh=3c095d9234c0 [accessed 2020-05-10]

59. Braithwaite I, Callender T, Bullock M, Aldridge RW. Automated and partly automated contact tracing: A systematic review to inform the control of COVID-19. Lancet 2020 Nov;2(11):e607-e621.

60. Saetta B. Il caso Singapore, il sistema investigativo (non solo) tecnologico per contrastare le epidemie, e la privacy. Valigia Blu. 2020 Mar 28. URL: https://www.valigiablu.it/approfondimenti/

il-caso-singapore-il-sistema-investigativo-non-solo-tecnologico-per-contrastare-le-epidemie-e-la-privacy/ [accessed 2020-05-15]

61. Altmann S, Milsom L, Zillessen H, Blasone R, Gerdon F, Bach R, et al. Acceptability of app-based contact tracing for COVID-19: Cross-country survey study. JMIR Mhealth Uhealth 2020 Aug 28;8(8):e19857 [FREE Full text] [doi: 10.2196/19857] [Medline: 32759102$]$

62. Anderson M, Auxier B. Most Americans don't think cellphone tracking will help limit COVID-19, are divided on whether it's acceptable. Pew Research Center. Washington, DC: Pew Research Center; 2020 Apr 16. URL: https://www. pewresearch.org/fact-tank/2020/04/16/ most-americans-dont-think-cellphone-tracking-will-help-limit-covid-19-are-divided-on-whether-its-acceptable/ [accessed 2020-05-15] 
63. Britton T, Ball F, Trapman P. A mathematical model reveals the influence of population heterogeneity on herd immunity to SARS-CoV-2. Science 2020 Aug 14;369(6505):846-849 [FREE Full text] [doi: 10.1126/science.abc6810] [Medline: $\underline{32576668]}$

64. Digital is transforming health, so why is consumer adoption stalling? Accenture 2020 Digital Health Customer Survey US results. Accenture. 2020. URL: https://www.accenture.com/ acnmedia/PDF-118/

Accenture-2020-digital-health-consumer-survey.pdf [accessed 2020-05-15]

\section{Abbreviations}

ACM: Association for Computing Machinery

EDPD: European Data Protection Board

EIPIN IS: European Intellectual Property Institutes Network-Innovation Society

FAQ: frequently asked questions

GDPR: General Data Protection Regulation

IEEE: Institute of Electrical and Electronics Engineers

PRISMA: Preferred Reporting Items for Systematic Reviews and Meta-Analyses

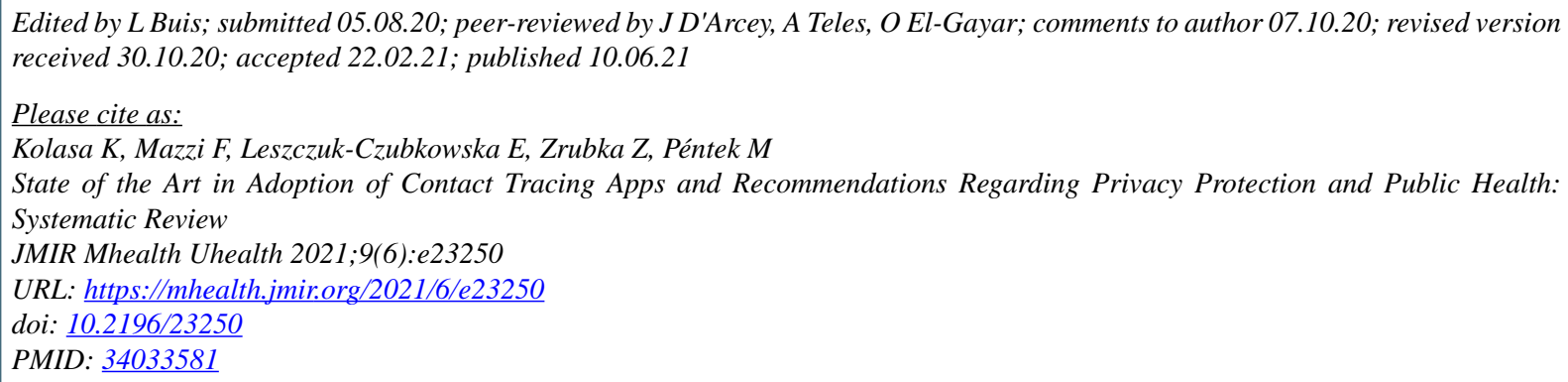

CKatarzyna Kolasa, Francesca Mazzi, Ewa Leszczuk-Czubkowska, Zsombor Zrubka, Márta Péntek. Originally published in JMIR mHealth and uHealth (https://mhealth.jmir.org), 10.06.2021. This is an open-access article distributed under the terms of the Creative Commons Attribution License (https://creativecommons.org/licenses/by/4.0/), which permits unrestricted use, distribution, and reproduction in any medium, provided the original work, first published in JMIR mHealth and uHealth, is properly cited. The complete bibliographic information, a link to the original publication on https://mhealth.jmir.org/, as well as this copyright and license information must be included. 